\title{
Commentary: Nitric oxide: Might make it better?
}

\author{
J. Hunter Mehaffey, MD, MSc, and Robert B. Hawkins, MD, MSc
}

\author{
From the Division of Thoracic and Cardiovascular Surgery, University of Virginia, Charlottesville, Va. \\ Disclosures: Authors have nothing to disclose with regard to commercial support. \\ Received for publication Aug 30, 2018; accepted for publication Aug 30, 2018; available ahead of print Oct 9 , \\ 2018. \\ Address for reprints: J. Hunter Mehaffey, MD, MSc, Department of Thoracic and Cardiovascular Surgery, PO Box \\ 800679, Charlottesville, VA 22908-0709 (E-mail: jhm9t@virginia.edu). \\ J Thorac Cardiovasc Surg 2019; 157:2339 \\ $0022-5223 / \$ 36.00$ \\ Copyright (C 2018 by The American Association for Thoracic Surgery \\ https://doi.org/10.1016/j.jtcvs.2018.08.070
}

Dr Kamenshchikov and colleagues ${ }^{1}$ are to be congratulated on a well-performed randomized controlled trial to evaluate the use of nitric oxide on cardiopulmonary bypass during coronary artery bypass grafting to blunt ischemiareperfusion injury. The authors used troponin I and creatine kinase $\mathrm{MB}$ as surrogates of cardiac injury and report the vasoactive inotropic score to quantify cardiac function. Although this is a provocative result, these metrics are surrogate end points with really unknown clinical significance. Surrogate end points have the advantage of being precise continuous variables where small differences can be detected. Although useful for early-stage clinical trials with limited power, they really are only hypothesis generating. In this trial of 60 patients, they failed to demonstrate a difference in ventilation time, intensive care, hospital length of stay, or any major complication. The clinical improvement will need to be high given the high cost of nitric oxide to make this a cost-effective adjuvant that practices are willing to try given the lack of direct reimbursement.

Looking further at the surrogate end points, we see they used troponin I levels postoperatively to measure myocardial ischemia. They demonstrate a statistically significant difference at 6 hours postoperatively (1.8 vs $2.4 \mathrm{ng} / \mathrm{mL})$. With a difference of only $0.6 \mathrm{ng} / \mathrm{mL}$, we are left to ponder the clinical significance of such a small improvement. Furthermore, as demonstrated by Beller and colleagues, ${ }^{2}$ the value of peak troponin after non-ST-segment elevation myocardial infarction had no effect on surgical outcomes for coronary artery bypass grafting. Therefore, although troponin may be a surrogate of myocardial injury, it likely has limited effect on surgical outcomes in standard cardiac operations. Perhaps if the authors had used a sicker patient population, such as patients with heart failure who underwent coronary bypass, they would have seen a larger attenuation of myocardial injury that may translate into improved clinical outcomes. This is possible as demonstrated in the randomized trial by Checchia and colleagues ${ }^{3}$ of nitric oxide during cardiopulmonary bypass in children

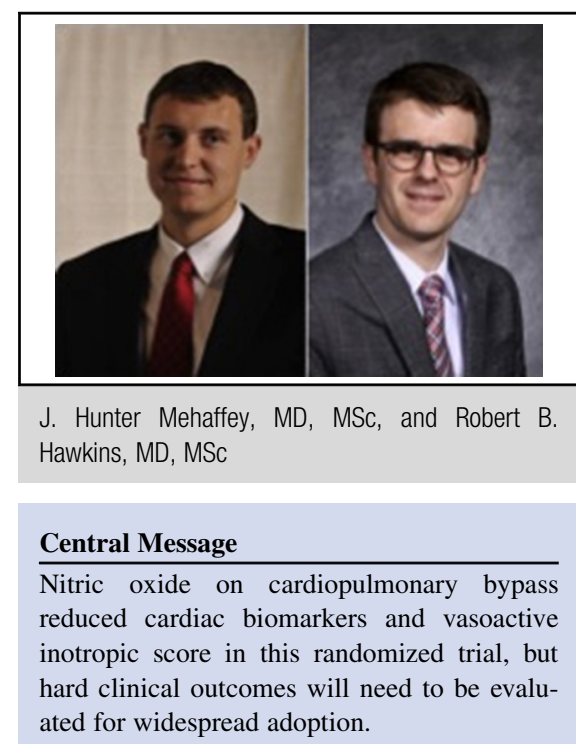

See Article page 2328. undergoing repair of tetralogy of Fallot. However, in the current study, it seems nitric oxide has limited clinical benefit during routine coronary artery bypass surgery.

Finally, the present study examined the vasoactive inotropic score to assess cardiac function postoperatively and demonstrated a significant reduction in support for the nitric oxide group. Although these data support the authors' conclusion, readers are left wondering about the clinical impact of this therapy. There are many strategies to improve myocardial protection during cardiopulmonary bypass, and nitric oxide likely represents an additional tool in the cardiac surgeon's armamentarium that can be used as needed in high-risk patients.

\section{References}

1. Kamenshchikov NO, Mandel IA, Podoksenov YK, Svirko YS, Lomivorotov VV Mikheev SL, et al. Nitric oxide provides myocardial protection when added to the cardiopulmonary bypass circuit during cardiac surgery: randomized trial. J Thorac Cardiovasc Surg. 2019;157:2328-36.e1.

2. Beller JP, Hawkins RB, Mehaffey JH, LaPar DJ, Kron IL, Yarboro LT, et al. Does preoperative troponin level impact outcomes after coronary artery bypass grafting? Ann Thorac Surg. 2018;106:46-51.

3. Checchia PA, Bronicki RA, Muenzer JT, Dixon D, Raithel S, Gandhi SK, et al. Nitric oxide delivery during cardiopulmonary bypass reduces postoperative morbidity in children-a randomized trial. J Thorac Cardiovasc Surg. 2013;146: $530-6$. 